\title{
PENERAPAN THARIQOH MUBASYIROH DALAM \\ PEMBELAJARAN BAHASA ARAB di SMPIT SALMAN Al \\ FARISI BOARDING SCHOOL YOGYAKARTA
}

\author{
Widi Astuti, Muhammad Fathoni, Ummu Salamah \\ STAI Masjid Syuhada Yogyakarta \\ Widi280990@gmail.com, muh.fathoni25@gmail.com
}

\section{ملخص}

تهدف هذه الدراسة إلى تحديد كيفية تطبيق تقليد المبسيرة في تعليم اللغة العربية والعوامل الداعمة والمثبطة في المدرسة الثانوية سلمان الفارسي الداخلية يو كياكرتا الفصل السابع ـ هذا البحث نوعي, تم جمع البيانات من خلال الملاحظة والمقابلات والتوثيق لاستكمال البيانات المراد تحليلها ـ بينما تم إجراء التحليل باستخدام التقنيات الوصفية. أظهرت النتائج : ( ) أن عملية تطبيق التقليد الإسلامي في تعلم اللغة العربية في مدرسة سلمان الفارسي الداخلية يوجياكارتا تتوافق مع مفهوم خطوات التعلم المباشر, r) العوامل الداعمة في تنفيذ تقليد المبسيرة في مدرسة سلمان الفارسي الداخلية في يوجياكارتا هي: مرافق إعلامية مدرسية مناسبة، وفصول دراسية مريحة، ومعلمون أكفاء ـ في حين أن العوامل المثبطة هي : قلة وقت التعلم، وقلة الكتب اليدوية، ليس لدى جميع الطلاب قواميس فردية، وعدم اهتمام الطلاب باللغة العربية مما يؤثر على دافع تعلم الطلاب. الكلمات المفتاحية : طريقة مباشرة ، تعليم اللغة العربية 
Widi Astuti, Muhammad Fathoni, Ummu Salamah : Penerapan Thariqoh Mubasyiroh dalam Pembelajaran Bahasa Arab di Smpit Salman Al Farisi Boarding School

Yogyakarta

\section{Pendahuluan}

Dalam proses belajar mengajar yang menjadi bagian terpenting adalah metode pengajaran. Metode mengajar merupakan salah satu faktor yang sangat mempengaruhi hasil belajar siswa. Dalam konteks metode pengajaran bahasa, metode merupakan satu rancangan menyeluruh untuk menyajikan secara teratur bahan-bahan bahasa, tak ada bagian-bagiannya yang saling bertentangan dan semuanya berdasarkan pada asumsi pendekatan tertentu. Dengan kata lain, metode adalah rencana menyeluruh mengenai penyajian bahasa secara sistematis berdasarkan pendekatan yang ditentukan.51 Jika kegiatan belajar mengajar dilakukan tanpa metode dan strategi sama halnya kegiatan tersebut terjadi dan dilakukan tanpa pedoman dan arah yang jelas. Akhirnya, target yang telah tersusun dan tertata rapi akan hancur dan tidak tercapai sama sekali. ${ }^{52}$

Oleh karena itu sangat penting bagi guru untuk mempunyai berbagai metode dan memiliki wawasan yang luas tentang bagaimana kegiatan mengajar itu terjadi, dan langkah-langkah apa saja yang harus ditempuh dalam kegiatan tersebut. Sehingga akan mudah bagi guru untuk memilih metode maupun strategi yang tepat untuk digunakan. Ketika hal tersebut terlaksana, maka hasil dan tujuan dari pembelajaran akan tercapai juga. Sebab suatu

${ }^{51}$ Muhajir, .......hlm. 217-218.

52 Ulin Nuha, Metodologi Super Efektif Pembelajaran Bahasa Arab, (Yogyakarta: Diva Press, 2012), hlm. 155 
Widi Astuti, Muhammad Fathoni, Ummu Salamah : Penerapan Thariqoh Mubasyiroh dalam Pembelajaran Bahasa Arab di Smpit Salman Al Farisi Boarding School Yogyakarta

metode yang bagus bisa jadi tidak cocok ketika diterapkan di pembelajaran lainnya. Salah satu metode dalam pembelajaran bahasa adalah metode langsung (direct method) dikatakan metode langsung karena guru langsung menggunakan bahasa Asing yang dipelajari sebagai alat mengajar dan berkomunikasi dalam ruang bahasa serta menghindari pemakaian bahasa ibu dan penerjemahannya. ${ }^{53}$

Pelajaran Bahasa Arab di SMPIT Salman Al Farisi Boarding School Yogyakarta merupakan mata pelajaran yang diharapkan mampu mengembangkan keterampilan berkomunikasi lisan dan tulisan. Pelajaran bahasa Arab ini berfungsi sebagai bahasa agama dan ilmu pengetahuan, disamping itu sebagai alat komunikasi. Berangkat dari observasi penulis di SMPIT Salman Al Farisi Boarding School Yogyakarta dapat diketahui bahwa sekolah tersebut menerapkan thariqah mubasyarah dalam pembelajaran bahasa Arab. Akan tetapi perkembangan kemahiran siswa dalam berbahasa Arab baik lisan atau tulisan masih kurang dari apa yang telah ditargetkan.

Adapun tujuan dalam penelitian ini adalah: 1) Mengetahui Penerapan Thariqah mubasyarah dalam Pembelajaran Bahasa Arab di SMPIT Salman Al Farisi Boarding School Yogyakarta, 2) Mengetahui Faktor Pendukung dan Penghambat dalam Penerapan Thariqah

${ }^{53}$ Fuad Abdul Halim, Proses Belajar Mengajar Bahasa, (Jakarta: Proyek Lembaga Pendidikan, 1987), hlm. 117. 
Widi Astuti, Muhammad Fathoni, Ummu Salamah : Penerapan Thariqoh Mubasyiroh dalam Pembelajaran Bahasa Arab di Smpit Salman Al Farisi Boarding School Yogyakarta

mubasyarah dalam Pembelajaran Bahasa Arab di SMPIT Salman Al Farisi Boarding School Yogyakarta.

\section{Penerapan Thariqah mubasyarah dalam Pembelajaran Bahasa} Arab di SMPIT Salman Al Farisi Boarding School Yogyakarta

Penelitian tentang Penerapan Thariqah mubasyarah dalam Pembelajaran Bahasa Arab di SMPIT Salman Al Farisi Boarding School Yogyakarta dilakukan dengan mengobservasi secara langsumg kegiatan pembelajaran kemudian menganalis masalah dengan landasan teori sebagai dasarnya. Hal ini dilakukan agar analisa data tepat dan akurat. Dari berbagai teori tentang thariqah mubasyarah, dapat kita simpulkan bahwa thariqah mubasyarah adalah suatu cara penyajian materi pelajaran bahasa asing dengan langkah guru langsung menggunakan bahasa tersebut dalam pembelajaran dan meminimalisir penggunaan bahasa ibu. Hal ini sama seperti yang diungkapkan Guru Bahasa Arab bahwa ketika pembelajaran berlangsung guru menggunakan bahasa asing dan menggunakan bahasa ibu ketika dibutuhkan saja. ${ }^{54}$

Ketika peneliti melaksanakan observasi secara langsung dalam pembelajaran bahasa arab, peneliti melihat proses belajar tersebut menggunakan bahasa asing secara langsung. Hal ini dibuktikan dengan pengenalan kosa kata bahasa arab menggunakan alat peraga tanpa menerjemahkan ke dalam bahasa

${ }^{54}$ Wawancara dengan bapak Shahibani selaku guru bahasa Arab pada hari Selasa 1 Oktober 2019, pukul 09.40 WIB. 
Widi Astuti, Muhammad Fathoni, Ummu Salamah : Penerapan Thariqoh Mubasyiroh dalam Pembelajaran Bahasa Arab di Smpit Salman Al Farisi Boarding School Yogyakarta

ibu. ${ }^{55}$ Menurut landasan teori tentang thariqah mubasyarah, fokus indikator pencapaian hanya pada istima' dan kalam saja. Akan tetapi karena tuntutan bagian kurikulum di SMPIT Salman Al Farisi Boarding School yang mengharuskan adanya empat kemahiran bahasa Arab yaitu istima', kalam, qira'ah, dan kitabah, maka dalam pembelajaran bahasa Arab tetap menjadikan keempat kemahiran pembelajaran bahasa Arab tersebut sebagai indikator pencapaian walaupun dengan menggunakan thariqah mubasyarah untuk keseluruhan pembelajaran di dalam kelas.

Pembelajaran bahasa Arab di SMPIT Salman Al Farisi Boarding School Yogyakarta berjalan selama delapan puluh menit atau dua kali jam pelajaran dalam satu minggu. Akan tetapi waktu tersebut dibagi menjadi dua, yaitu satu jam pelajaran di hari Rabu dan satu jam pelajaran di hari Jum'at. Karena pembagian jam tersebut, maka strategi pembelajaran dibagi menjadi dua. Dua strategi pada pertemuan hari Rabu dan dua strategi pada hari Jum'at. Informan menyampaikan bahwa pembelajaran bahasa arab dimulai dengan mengulang kosa kata materi sebelumnya dan diakhiri dengan penampilan khiwar berpasang di depan kelas secara bergiliran. ${ }^{56}$ Adapun secara keseluruhan pembelajaran akan dijelaskan berikut ini yaitu:

55 Observasi Kelas pada hari Rabu, 2 Oktober 2019, pukul 13.00-13.40 WIB.

${ }^{56}$ Wawancara dengan bapak Shahibani selaku guru bahasa Arab pada hari Selasa, 1 Oktober 2019, pukul. 10.00 WIB 
Widi Astuti, Muhammad Fathoni, Ummu Salamah : Penerapan Thariqoh Mubasyiroh dalam Pembelajaran Bahasa Arab di Smpit Salman Al Farisi Boarding School

Yogyakarta

1. Langkah awal yang dilakukan oleh guru dalam pembelajaran adalah dengan salam, menanyakan kabar dan membuat kelas supaya menjadi hidup dan anak-anak bersemangat. Dalam hal ini guru membuat permaian tebak kosa kata yang telah diberikan dari materi-materi yang sudah diberikan dengan menggunakan gambar ataupun benda langsung yang ditujukan kepada siswa secara acak, sehingga siswa harus fokus kepada guru..$^{57}$

Dalam langkah awal ini, guru menggunakan waktu 3-5 menit untuk mengulang kosa kata yang telah dihafalkan oleh siswa. Contoh pertanyaan yang ditanyakan oleh guru kepada siswa : يانورة ماهذا؟ (guru memberikan pertanyaan sambil menunjuk gambar yang telah ditampilkan di slide photo ketika pembelajaran berlangsung), kemudian siswa menjawab sesuai dengan gambar maupun benda yang ditanyakan dan jika jawaban salah, siswa maka siswa mendapat hukuman berdiri di depan kelas sampai pembelajaran selesai..$^{58}$

2. Setelah semua siswa fokus, maka guru memasuki materi pembelajaran selanjutnya. Tahap awal yang dilakukan guru

57 Wawancara dengan guru bahasa Arab pada hari Selasa, 1 Oktober 2019, pukul 08.20 WIB

58 Observasi Kelas pada hari Rabu, 2 Oktober 2019, pukul 13.00-13.40 WIB. 
Widi Astuti, Muhammad Fathoni, Ummu Salamah : Penerapan Thariqoh Mubasyiroh dalam Pembelajaran Bahasa Arab di Smpit Salman Al Farisi Boarding School Yogyakarta

adalah mengenalkan kosa kata baru dengan benda yang ada di kelas maupun dengan gambar yang berkaitan dengan materi. ${ }^{59}$

Dalam langkah ini, guru menggunakan slide photo untuk menambah kosa-kata, di dalam slide photo tersebut sudah tertulis nama benda dengan bahasa Arab. Kemudian sambil menunjuk gambar guru memberikan pertanyaan, dan siswa menjawab sesuai dengan kosa kata yang ada di dalam gambar. Contoh :

$$
\begin{aligned}
& \text { ما هذا؟؟ } \\
& \text { هذا كوب : Siswa } \\
& \text { ما هذا؟؟: Guru } \\
& \text { Siswa : هذا مكتب }
\end{aligned}
$$

Guru mengulang sampai 3 kali pertanyaan tersebut atau lebih sampai sekiranya siswa hafal dengan kosa kata baru tersebut. Dalam setiap pertemuan, guru memberikan tiga kosa kata baru untuk dihafalkan.

Ketika guru menyampaikan kosa kata baru, ada beberapa siswa yang tidak memperhatikan guru. Langkah guru mengatasi hal tersebut dengan mendekati siswa dan memberikan pertanyaan tentang kosa kata baru yang telah disampaikan. ${ }^{60}$

59 Wawancara dengan guru bahasa Arab pada hari Selasa, 1 Oktober 2019, pukul 08.20 WIB

60 Observasi kelas pada hari Rabu, 9 Oktober 2019, pukul 13.00-13.40 WIB. 
Widi Astuti, Muhammad Fathoni, Ummu Salamah : Penerapan Thariqoh Mubasyiroh dalam Pembelajaran Bahasa Arab di Smpit Salman Al Farisi Boarding School

Yogyakarta

3. Setelah kosa kata dihafal, guru memberikan dialog pendek dengan kosa kata tersebut. Contoh :

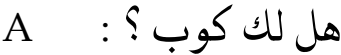
B

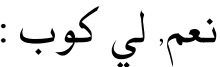
A أين كوبك؟
B كوب على المكتب

Tahap awal, guru berperan menjadi tokoh A, dan semua siswa secara klasikal menjadi tokoh B. Setelah semua siswa hafal, guru menunjuk siswa secara acak untuk diajak berdialog. Setelah itu siswa maju bergiliran ke depan kelas berpasangan dua-dua untuk memperagakan dialog yang sudah dihafal. Akan tetapi karena waktu pembelajaran yang tidak panjang, maka pemeragaan dialog dalam sekali pembelajaran hanya sebagian siswa dan sebagian lagi pada pertemuan berikutnya.

4. Langkah b dan c di atas adalah langkah pada pertemuan pertama pembelajaran bahasa Arab, sedangkan langkah a, dalam setiap pertemuan guru selalu mempraktikkan langkah tersebut untuk membuat siswa fokus dalam pembelajaran.

Kemudian pada pertemuan kedua, setelah guru menerapkan langkah a, guru menulis kosa kata dan dialog di papan tulis atau terkadang guru hanya memakai slide yang berisi kosa kata dan dialog tersebut. Di saat itu pula semua siswa

\section{0}


Widi Astuti, Muhammad Fathoni, Ummu Salamah : Penerapan Thariqoh Mubasyiroh dalam Pembelajaran Bahasa Arab di Smpit Salman Al Farisi Boarding School Yogyakarta

dihimbau untuk menulis di buku catatan masing-masing kosa kata dan dialog tersebut. Saat siswa menulis, guru mengontrol siswa dengan berkeliling kelas memastikan semua siswa menulis. ${ }^{61}$

5. Setelah semua siswa selesai menulis, untuk mengembangkan keterampilan membaca anak-anak, guru dan semua siswa membaca tulisan masing-masing bersama-sama sambil meneliti ulang tulisan. Setelah membaca klasikal selesai, guru menunjuk siswa secara individu untuk membaca kembali tulisan mereka. ${ }^{62}$

6. Langkah terakhir dalam pembelajaran bahasa Arab ini adalah dengan evaluasi. Guru memberikan evaluasi dengan memberikan beberapa pertanyaan kepada siswa baik itu mengenai kosa kata maupun dialog yang sudah di hafal atau dengan mengerjakan latihan-latihan yang diberikan oleh guru dari buku paket. Kemudian sambil menunggu jam keluar, sebagian siswa yang belum maju memperagakan dialog dipersilahkan untuk bergiliran maju ke depan kelas. ${ }^{63}$ WIB.

${ }^{61}$ Observasi kelas pada hari Jumat, 11 Oktober 2019, pukul 07.00-07.40 62 Observasi kelas pada hari Jumat, 11 Oktober 2019, pukul 07.00-07.40 WIB.

63 Observasi kelas pada hari Jumat, 11 Oktober 2019, pukul 07.00-07.40 WIB. 
Widi Astuti, Muhammad Fathoni, Ummu Salamah : Penerapan Thariqoh Mubasyiroh dalam Pembelajaran Bahasa Arab di Smpit Salman Al Farisi Boarding School

Yogyakarta

Dari keterangan-keterangan di atas, dapat dilihat bagaimana langkah-langkah penerapan thariqah mubasyarah yang dilakukan guru bahasa Arab di SMPIT Salman Al Farisi Boarding School Yogyakarta. Peneliti menyimpulkan, guru tersebut memiliki cara tersendiri untuk mengemas penerapan thariqah mubasyarah dalam pembelajaran bahasa Arab. Hal ini dibuktikan dengan adanya beberapa perbedaan langkah-langkah thariqah mubasyarah yang terdapat dalam teori thariqah mubasyarah di buku Metodologi Pembelajaran Bahasa Arab karya Acep Hermawan yang menjelasakan dari bagian awal pembelajaran hingga tahap akhir pembelajaran yang hanya memfokuskan pada pembelajaran istima' dan kalam saja. Sedangkan di SMPIT Salman Al Farisi Boarding School Yogyakarta guru bahasa Arab menambahkan pembelajaran kitabah dan qira'ah.

Namun secara keseluruhan, langkah pembelajaran di atas tidak keluar dari teori yang telah ditulis oleh Acep Hermawan. Karena langkah-langkah thariqah mubasyarah yang ditulis oleh Acep Hermawan semuanya tetap diterapkan oleh guru dalam pembelajaran, hanya saja guru menambahkan beberapa langkah agar kelas menjadi lebih hidup. Seperti menambahkan permainan tebak kosa kata agar semua siswa bisa fokus saat pembelajaran. Dari keterangan di atas pula peneliti dapat mengambil kesimpulan bahwa peran guru aktif saat pembelajaran berlangsung. Hal ini dibuktikan dengan langkah-langkah pembelajaran yang guru terapkan. Sedangkan untuk peran siswa di dalam kelas, terkadang 
Widi Astuti, Muhammad Fathoni, Ummu Salamah : Penerapan Thariqoh Mubasyiroh dalam Pembelajaran Bahasa Arab di Smpit Salman Al Farisi Boarding School Yogyakarta

ada beberapa siswa yang tidak fokus dan menjadikan siswa tersebut tidak aktif.

Faktor Pendukung dan Faktor Penghambat Penerapan Thariqah Mubasyarah dalam Pembelajaran Bahasa Arab Di SMPIT Salman Al Farisi Boarding School Yogyakarta

Dalam setiap pembelajaran di dalam kelas pastinya selalu terdapat faktor pendukung dan faktor penghambat. Hal ini juga terjadi dalam pembelajaran bahasa Arab di SMPIT Salman Al Farisi Boarding School Yogyakarta. Untuk lebih lanjut, peneliti akan menjelaskan faktor pendukung dan faktor penghambat dalam pembelajaran bahasa arab di SMPIT Salman Al Farisi Boarding School Yogyakarta sebagai berikut :

\section{Faktor Pendukung}

Faktor pendukung dalam pembelajaran bahasa Arab di SMPIT Salman Al Farisi adalah sebagai berikut:

a. Fasilitas media pembelajaran di kelas yang sesuai dengan thariqah mubasyarah

Ketika pembelajaran bahasa Arab berlangung, guru selalu menggunakan alat peraga, LCD maupun slide dalam pembelajaran yang berupa power point. Dengan adanya 
Widi Astuti, Muhammad Fathoni, Ummu Salamah : Penerapan Thariqoh Mubasyiroh dalam Pembelajaran Bahasa Arab di Smpit Salman Al Farisi Boarding School

Yogyakarta

fasilitas pembelajaran tersebut, pembelajaran bahasa Arab berjalan lancar. ${ }^{64}$

b. Ruang kelas yang nyaman

Hal ini terlihat dari penataan ruang kelas yang rapi, wangi, dan terdapat hiasan-hiasan di kelas kreasi siswa. ${ }^{65}$

c. Guru yang kompeten

Guru bahasa Arab di SMPIT Salman Al Farisi Boarding School Yogyakarta adalah lulusan S1 pertanian, akan tetapi guru tersebut menguasai bahasa Arab. Baik dari segi bahasa Arab sendiri, metode dan strategi pembelajaran bahasa, maupun media yang digunakan dalam pembelajaran bahasa Arab. Guru tersebut memperlajari bahasa arab sejak bangku Sekolah Menengah Pertama sampai Sekolah Menengah Atas di Pondok Pesantren Al Irsyad Salatiga dan sering mengikuti daurah-daurah yang berhubungan dengan bahasa Arab. Dalam pengucapan kata yang berbasa Arab pun guru sangat jelas, baik fashahah hurufnya maupun intonasinya. ${ }^{66}$

2. Faktor Penghambat

Saat wawancara terhadap guru mata pelajaran bahasa Arab, guru menjelaskan bahwa dalam setiap pembelajaran, guru selalu memaksimalkan penggunaan thariqah mubasyarah dan

${ }^{64}$ Observasi sekolah pada hari Selasa, 1 Oktober 2019, pukul 07.00 WIB.

65 Observasi sekolah pada hari Selasa, 1 Oktober 2019, pukul 07.00 WIB

${ }^{66}$ Observasi kelas pada hari Rabu, 2 Oktober 2019, pukul 13.00-13.40 WIB. 
Widi Astuti, Muhammad Fathoni, Ummu Salamah : Penerapan Thariqoh Mubasyiroh dalam Pembelajaran Bahasa Arab di Smpit Salman Al Farisi Boarding School Yogyakarta

berusaha membuat kelas hidup dengan semangat para siswa. ${ }^{67}$ Guru menjelaskan saat pembelajaran berlangsung tidak semua siswa berantusias untuk mengikuti pembelajaran. Terkadang siswa asyik mengobrol dengan teman sebelah atau mengantuk saat pembelajaran. Oleh karena itu guru selalu menegur siswa ketika sudah mulai tidak fokus pembelajaran. Ketika siswa berantusias maka hampir semua yang telah diajarkan oleh guru di dalam kelas bisa cepat ditangkap oleh siswa, baik dari segi hafalan, penulisan, maupun bacaan. ${ }^{68}$

Hal di atas menunjukkan bahwa salah satu faktor penghambat pembelajaran bahasa arab adalah kurangnya keaktifan siswa saat pembelajaran berlangsung. Adapun faktor penghambat lainnya akan dijelaskan sebagai berikut:

a. Waktu pembelajaran yang kurang

Waktu pembelajaran bahasa Arab di SMPIT Salman Al Farisi Boarding School Yogyakarta hanya dua kali jam pelajaran setiap satu pekannya. Sedangkan satu jam pelajaran hanya 40 menit saja. Dengan menggunakan empat strategi pembelajaran informan menyampaikan waktu jam pelajaran sangat kurang. 69

${ }^{67}$ Wawancara dengan bapak Shahibani selaku guru bahasa Arab pada hari Sabtu 5 oktober 2019, pukul 13.00 WIB.

68 Wawancara dengan bapak Shahibani selaku guru bahasa Arab pada hari Sabtu 5 oktober 2019, pukul 13.00 WIB.

69 Wawancara dengan bapak Shahibani selaku guru bahasa Arab pada hari Selasa, 1 Oktober 2019, pukul 08.20 WIB 
Widi Astuti, Muhammad Fathoni, Ummu Salamah : Penerapan Thariqoh Mubasyiroh dalam Pembelajaran Bahasa Arab di Smpit Salman Al Farisi Boarding School

Yogyakarta

b. Keterbatasan buku panduan

Perpustakaan SMPIT Salman Al Farisi Boarding School Yogyakarta memang menyediakan buku paket bahasa Arab, yaitu buku "Ayo Memahami Bahasa Arab" penerbit Erlangga. Akan tetapi untuk saat ini buku tersebut tidak dipakai karena ada pergantian buku panduan yaitu buku "Durusu Allughah". Karena belum ada pembelanjaan buku, maka untuk saat buku panduan bahasa Arab hanya dimiliki oleh guru saja, sehingga siswa tidak bisa belajar mandiri ketika di luar pembelajaran bahasa Arab. ${ }^{70}$

c. Tidak semua siswa memiliki pegangan kamus

Salah satu kunci dari pembelajaran bahasa asing adalah menguasai kosa kata dari bahasa asing tersebut, dan salah satu cara untuk menunjang adalah dengan kamus bahasa. Karena jika mendengar kosa kata yang asing atau baru bisa mencari dengan kamus untuk mengetahui artinya, akan tetapi tidak semua siswa kelas VII B SMPIT Salaman Al Farisi Boarding School Yogyakarta memiliki kamus individu.

d. Kurangnya minat siswa terhadap bahasa Arab

Guru mata pelajaran bahasa Arab menyampaikan salah satu faktor kurangnya motivasi belajar bahasa Arab pada siswa kelas VII B dikarenakan belum tumbuhnya minat WIB.

70 Observasi perpustakaan pada hari Senin, 7 Oktober 2019, pukul 09.40 
Widi Astuti, Muhammad Fathoni, Ummu Salamah : Penerapan Thariqoh Mubasyiroh dalam Pembelajaran Bahasa Arab di Smpit Salman Al Farisi Boarding School Yogyakarta

mereka terhadap bahasa Arab. ${ }^{71} \mathrm{Hal}$ ini terlihat saat pembelajaran berlangsung ada siswa yang mengantuk atau bercanda di dalam kelas dan tidak memperhatikan guru saat menyampaikan materi. ${ }^{72}$

\section{Kesimpulan}

Dari keterangan di atas dapat disimpulkan bahwa :

1. Proses penerapan thariqah mubasyarah dalam pembelajaran bahasa Arab di SMPIT Salman Al Farisi Boarding School Yogyakarta sudah sesuai dengan konsep langkah pembelajaran dengan thariqah mubasyarah.

2. Adapun faktor pendukung dalam pembelajaran bahasa Arab di SMPIT Salman Al Farisi Boarding School Yogyakarta yaitu: fasilitas media sekolah yang memadai dan ruang kelas yang nyaman, dan guru yang kompeten. Sedangkan faktor penghambatnya yaitu: waktu pembelajaran yang kurang, keterbatasan buku panduan, tidak semua siswa memiliki kamus individu, dan kurangnya minat siswa terhadap Bahasa Arab.

${ }^{71}$ Wawancara dengan bapak Shahibani selaku guru bahasa Arab pada hari Sabtu, 5 Oktober 2019, pukul. 13.00 WIB.

72 Observasi kelas pada hari Rabu, 2 Oktober 2019, pukul 13.00-13.40 WIB. 
Widi Astuti, Muhammad Fathoni, Ummu Salamah : Penerapan Thariqoh Mubasyiroh dalam Pembelajaran Bahasa Arab di Smpit Salman Al Farisi Boarding School Yogyakarta

\section{DAFTAR PUSTAKA}

Abdul Hamid, Uril Baharuddin, dan Bisri Mustofa, Pembelajaran Bahasa Ara Pendekatan, Metode, Strategi, Materi, dan Media. Malang: UIN Malang Press, 2008

Acep Hermawan, Metodologi Pembelajaran Bahasa Arab. Bandung: Remaja Rosdakarya, 2014

Ahmad Fuad Effendy, Metodologi Pengajaran Bahasa Arab. Malang:Misykat Malang, 2014

Ahmad Izzan, Metodologi Pembelajaran Bahasa Arab. Bandung: Humaniora, 2009

Bisri Musthafa dan Abul Hamid, MetodeE Strategi Pembelajaran Bahasa Arab. Malang: UIN Maliki Press, 2012

Burhan Bungin, Penelitian Kualitatif: Komunikasi, Ekonomi, Kebijakan Publik, dan Ilmu Sosial Lainnya. Jakarta: Kencana, 2007

Chaidar Alwasilah, Metodologi Pembelajaran Bahasa Arab. Bandung:Remaja Rosdakarya, 2012

Deddy Mulyana, Metodologi Penelitian Kualitatif: Paradigma Baru Ilmu Komunikasi dan Ilmu Sosial Lainnya. Bandung: Remaja Rosdakarya, 2010

Fuad Abdul Hamied, Proses Belajar Mengajar Bahasa, Jakarta: Proyek Lembaga Pendidikan, 1987

L. J. Moloeng, Metode Penelitian Kualitatif. Bandung: Remaja Rosdakarya, 2002

Lathifiyana Oktavia, Penerapan Metode Langsung dalam meningkatkan ketrampilan berbicara bahasa Arab di kelas VII A MTs Miftahul Huda Maguan Kaliori Rembang (Penelitian Tindakan Kelas), 
Widi Astuti, Muhammad Fathoni, Ummu Salamah : Penerapan Thariqoh Mubasyiroh dalam Pembelajaran Bahasa Arab di Smpit Salman Al Farisi Boarding School Yogyakarta

MTs Miftahul Huda Maguan Kaliori Rembang (Skripsi), Yogyakarta: Universitas Islam Negeri Sunan Kali Jaga, 2010

Muhajir, Arah Baru Pengajaran Bahasa Arab, Yogyakarta: Fakultas Ilmu Tarbiyah dan Ilmu Keguruan UIN Sunan Kalijaga, 2017

Muhammad Iskandar Zulkarnaen, Penerapan Metode Langsung (Manhaj Al Mubaasyir) dalam pengajaran bahasa Arab bagi siswa kelas $1 b$ MTs Pondok Pabelan Mungkid Magelang, MTs Pondok Pabelan Magelang (Skripsi) Yogyakarta: IAIN Sunan Kalijaga, 2003

Mukhtar, Metode Praktis Penelitian Deskriptif Kualitatif. Jakarta: referesnsi, 2013

Muljanto Sumardi, Pengajaran Bahasa Asing; Sebuah Tinjauan dari Segi Metodologi, Jakarta: Bulan Bintang, 1974

Musthafa Al-Ghulayani, Jami' Ad-Durus Al-Arabiyah. Beirut: AlMaktabah Al Misriyah, 1987

Radliyah Zaenuddin, dkk, Metodologi dan Strategi Alternatif Pembelajaran BahasaArab, Cirebon: Pustaka Rihlah Group, 2005

Suharso dan Ana Retnoningsih, Kamus Besar Bahasa Indonesia. Semarang:Widya Karya, 2011

Sugiono, Metode Penelitian Pendidikan: Pendekatan Kuantitatif, Kualitatif, danRED, Bandung: Alfabeta, 2013.

Suharsimi Arikunto, Peosedur Penelitian Suatu Pendekatan Praktek. Jakarta:PT. Rineka Cipta, 2013

Tayar Yusuf dan Saiful Anwar, Metodologi Pengajaran Agama dan Bahasa Arab,Jakarta: Rajawali Press, 1994 
Widi Astuti, Muhammad Fathoni, Ummu Salamah : Penerapan Thariqoh Mubasyiroh dalam Pembelajaran Bahasa Arab di Smpit Salman Al Farisi Boarding School

Yogyakarta

Trianto, Mendesain Model Pembelajaran Inovatif-Progresif. Jakarta: Kencana Premada Media Group, 2010

Ulin Nuha, Metodologi Super Efektif Pembelajaran Bahasa Arab,Yogyakarta: Diva Press, 2012 